\title{
Chemical Constitutions and Antioxidant Activities of Tomato Leaf Extracts
}

\author{
Kyung Jun Lee ${ }^{1}$, Gi-An Lee ${ }^{1}$, Kyung-Ho Ma $^{1}$, Sebastin Raveendar ${ }^{1}$, Yang-Hee Cho ${ }^{1}$, Jung-Ro Lee ${ }^{1 *}$, \\ Jong-Wook Chung ${ }^{2}$ * \\ ${ }^{1}$ National Agrobiodiversity Center, National Agro-biodiversity Center, Rural Development Administration, Jeonju 54874, Korea \\ ${ }^{2}$ Department of Industrial Plant Science and Technology, Chungbuk National University, Cheongju 28644, Korea
}

\begin{abstract}
The present study aimed to determine the contents of five flavonols and two glycoalkaloids as well as the antioxidant activities of leaf ethanol extracts of 50 tomato accessions. The antioxidant activity was assessed using different tests: $2,2^{\prime}$-azino-bis (3-ethylbenzothiazoline-6-sulphonic acid) (ABTS), 2,2-diphenyl-1-picryl hydrazyl (DPPH), nitric oxide (NO), and total polyphenol content (TPC). Flavonols and glycoalkaloids contents were determined using a high performance liquid chromatography-diode array detector system. Among five flavonols and two glycoalkaloids, naringenin and tomatine were detected in tomato leaves at high concentrations. Of the 50 tomato accessions, IT 229711, IT2365203, and IT 207224 were found to have the highest contents of quercetin, kaempferol, and tomatine, respectively. Leaf extract of IT189949 exhibited the highest relative antioxidant capacity index (RACI). Among the five flavonols, myricetin showed positive correlations with DPPH, ABTS, and NO, while isorhamnetin had positive correlation with DPPH. These results will expand the chemical constitution database and provide information on tomato leaves. They are valuable for the development of functional foods or feed-additives.
\end{abstract}

Keywords Antioxidant activity, Flavonol, Glycoalkaloids, Leaf extracts, Tomato

\section{INTRODUCTION}

Tomato (Lycopersicon esculentum Mill) is a widely studied species. However, only a few research studies have focused on tomato leaves (Taveira et al. 2012). Although this plant material is considered a by-product of tomato production, it contains several bioactive metabolites, including steroidic alkaloids (Friedman 2002) and phenolics such as hydroxycinnamic acids and flavonoids (Slimestad and Verheul 2009; Ferreres et al. 2011). These compounds are known to be involved in host-plant defenses. In addition, they have several pharmacological and nutritional functions in humans (Friedman 2002).

Flavonoids are structurally diverse nonvolatile plant specialized metabolites, including chalcones, flavanones, flavones, flavonols, and anthocyanins (Buer et al. 2010).
Flavonols, a subclass of flavonoids, include kaempferol, quercetin, and myricetin. They are relatively widespread and abundant in plants (Herrmann 1976). Flavonols are effective radical scavengers and potential chain-breaking antioxidants in lipid oxidation reactions (Hopia and Heinonen 1999).

Steroidal alkaloids are secondary metabolites of Solanaceae. In tomato, these compounds have characteristic C27 cholestane skeleton with an oxa-azaspirodecane system (spirosolane) in $22 \mathrm{~S}$ or $25 \mathrm{~S}$ configuration (Taveira et al. 2014). Tomatine is the major alkaloid. It is composed of aglycone tomatidine and a tetrasaccharide residue containing d-galactose, two molecules of d-glucose, and d-xylose. Steroidal alkaloids from tomato have several biological activities, including antiviral, anti-fungal, antibacterial, anti-inflammatory, cholesterol lowering, and

Received May 28, 2016; Revised June 20, 2016; Accepted June 21, 2016; Published August 31, 2016

*Corresponding author Jung-Ro Lee, jrmail@korea.kr, Tel: +82-63-238-4880, Fax: +82-63-238-4879

Jong-Wook Chung, jwchung73@chungbuk.ac.kr, Tel: +82-43-261-2518, Fax: +82-43-271-0413

*These authors contributed equally to this paper as co-corresponding authors. 
immunopotentiating properties (Friedman 2002; Khalid et al. 2004; Milner et al. 2011; Friedman 2013; Singh et al. 2013).

Antioxidant compounds have received attention from natural-product consumers and researchers due to their pharmacological properties. Antioxidants can lower oxidative stress caused by reactive oxygen species (Nordberg and Arnér 2001). There is an increasing interest in natural antioxidant products for use as medicines and food additives (Mossi et al. 2004; Willcox et al. 2004). Phytochemicals such as polyphenols and carotenoids are important because of their contributions to human health with multiple biological effects such as antioxidant, antimutagenic, anticarcinogenic, and cytoprotective activities (Ajila and Prasada Rao 2008). The objective of this study was to isolate and identify flavonols and glycoalkaloids from tomato leaves of 50 accessions and determine their antioxidant properties through 2,2-diphenyl-1-picryl hydrazyl (DPPH), 2,2'-azino-bis(3-ethylbenzothiazoline6-sulphonic acid) (ABTS), total polyphenol content (TPC), and nitric oxide (NO) assays.

\section{MATERIALS AND METHODS}

\section{Plant materials}

Fifty tomato accessions were obtained from the National Agro-biodiversity Center of the Rural Development Administration, Republic of Korea (http://genebank.rda.go.kr). These accessions were grown in an experimental field in 2014. Leaf samples were dried at $40^{\circ} \mathrm{C}$ for 4 days. Crude extracts were produced from $7 \mathrm{~g}$ of oven-dried tomato leaves using an ASE-200 (Dionex, Sunnyvale, CA, USA) extractor. Extractions were performed in $40-\mathrm{ml} 75 \%$ ethanol under nitrogen gas at a pressure of 1,500 psi and temperature of $70^{\circ} \mathrm{C}$. Extracted samples were dried using a Genevac HT-4X vacuum concentrator (Genevac, Suffolk, UK).

\section{Analysis of flavonol aglycones}

Fifty milligrams of extract were mixed with $10 \mathrm{ml}$ of $1 \mathrm{~N}$ $\mathrm{HCl}$ at $80^{\circ} \mathrm{C}$ for 2 hours followed by addition of $10 \mathrm{ml}$ absolute EtOH. The mixture was shaking at $150 \mathrm{rpm}$ for 2 hours. After centrifugation at 13,000 rpm for 10 minutes, each specimen was filtered through a $0.45 \mu \mathrm{m}$ syringe filter and analyzed with Agilent 1260 Infinity high performance liquid chromatography (HPLC) system (Agilent Technologies, Santa Clara, CA, USA). The analysis was performed using a prodigy ODS column $(250 \times 4.6 \mathrm{~mm}, 5 \mu \mathrm{m}$ particle, Phenomenex). HPLC conditions were as follows: solvent $\mathrm{A}, 0.5 \% \mathrm{H}_{3} \mathrm{PO}_{4} / \mathrm{H}_{2} \mathrm{O}$; solvent $\mathrm{B}$, Methanol; gradient, $30 \%$ (B) for 0 to 40 minutes, $20 \%$ (B) for 40 to 42 minutes, hold at 20\% (B) for 42 to 44 minutes, and 50\% (B) for 44 to 50 minutes; column temperature, $30^{\circ} \mathrm{C}$; and flow rate, 1 $\mathrm{ml} / \mathrm{min}$. The filter detector was set at $370 \mathrm{~nm}$.

\section{Analysis of steroid glycoalkaloids}

Fifty milligrams of extract were mixed with $15 \mathrm{ml}$ of 0.5 $\mathrm{N} \mathrm{HCl}$ at $80^{\circ} \mathrm{C}$ for 2 hours. After centrifugation at 5,000 rpm for 15 minutes, clean supernatants were transferred to new tubes. Each specimen was mixed with $15 \mathrm{ml}$ of ammonia solution and incubated at $80^{\circ} \mathrm{C}$ for 2 hours. After centrifugation at 5,000 rpm for 15 minutes, clean supernatants were transferred to new tubes and incubated at $4^{\circ} \mathrm{C}$ for 12 hours. After centrifugation at 5,000 rpm for 15 minutes, clean supernatants were transferred to new tubes and evaporated to remove ammonia solution. The residue was reconstituted in $2 \mathrm{ml}$ tetrahydrofuran/acetronitrile/20 $\mathrm{mM} \mathrm{KH} \mathrm{PO}_{4}(50: 25: 25, \mathrm{v} / \mathrm{v} / \mathrm{v})$. After centrifugation at $5,000 \mathrm{rpm}$ for 15 minutes, each specimen was filtered through a $0.45 \mu \mathrm{m}$ syringe filter and analyzed with the Agilent 1260 Infinity HPLC system. The analysis was performed using a prodigy ODS column $(250 \times 4.6 \mathrm{~mm}, 5$ $\mu \mathrm{m}$ particle, Phenomenex). HPLC conditions were as follows: solvent A, Acetonitrile, solvent B, $50 \mathrm{mM}$ Ammonium phosphate (pH 3.0 O; gradient, 75\% (B) for 0 to 12 minutes, $65 \%$ (B) for 12 to 15 minutes, $55 \%$ (B) for 15 to 17 minutes, $35 \%$ (B) for 17 to 25 minutes, and $80 \%$ (B) for 25 to 30 minutes; column temperature, $30^{\circ} \mathrm{C}$; and flow rate, $1 \mathrm{ml} / \mathrm{min}$. The filter detector was set at $208 \mathrm{~nm}$.

\section{DPPH assay}

DPPH radical-scavenging activities of the extracts were assessed using the method of Lee and Lee (2004) with slight modifications. Briefly, DPPH solution (150 $\mu$ l; 150 $\mu \mathrm{M}$ in anhydrous EtOH) was added to $100 \mu \mathrm{l}$ of sample 
solution. The mixture was shaken vigorously and left to stand at $25^{\circ} \mathrm{C}$ in the dark for 30 minutes. Absorbance at 517 $\mathrm{nm}$ was measured using a spectrophotometer (Epoch; Bio-Tek, Winooski, VT, USA). Results were expressed as IC50 and compared to ascorbic acid standard.

\section{ABTS assay}

ABTS radical-scavenging activity was estimated using the method of Re et al. (1999) with modifications. Briefly, the ABTS radical cation was generated by adding $7 \mathrm{mM}$ ABTS to $2.45 \mathrm{mM}$ potassium persulfate followed by overnight incubation in the dark at room temperature. The ABTS radical cation solution was diluted with $\mathrm{MeOH}$ to obtain an absorbance of $0.7 \pm 0.02$ at $735 \mathrm{~nm}$. The diluted ABTS radical cation solution $(190 \mu \mathrm{l})$ was added to $10 \mu \mathrm{l}$ of sample solution. After 6 minutes of incubation at room temperature, the absorbance at $735 \mathrm{~nm}$ was measured using a spectrophotometer (Epoch; Bio-Tek). Trolox was used as standard. Results were expressed in $\mu \mathrm{g}$ of Trolox equivalent per mg of dried sample.

\section{Total polyphenol content assay}

TPC was measured using modified Folin-Ciocalteu method (Waterhouse 2001). Folin-Ciocalteu reagent (100 $\mu \mathrm{l})$ was added to $100 \mu \mathrm{l}$ of sample solution and reacted at room temperature for 3 minutes. After adding $100 \mu 12 \%$ sodium carbonate, the mixture was incubated at room temperature for 30 minutes. Absorbance was measured at $750 \mathrm{~nm}$ on an spectrophotometer (Epoch; Bio-Tek) with distilled water as blank. Total phenolic content was reported as milligrams of gallic acid equivalents (GAE) per gram of dry weight sample (mg GAE $\mathrm{g}^{-1}$ dry seed).

\section{Nitric oxide-scavenging activity}

The NO-scavenging activity of each plant extract was determined using the method of Tsai et al. (2007). In order to determine the effect of tomato leaf extract on NO production, $1 \times 10^{5}$ RAW 264.7 cells were seeded into 96-well culture plates. Following 24 hours of incubation, adherent cells were washed three times with phosphate buffer saline. These cells were then incubated in prepared Dulbecco's modified Eagle's medium containing extracts from various concentration of tomato leaves with or without lipopolysaccaride (LPS) (100 ng/ml). Following 24 hours of incubation, the medium was collected for nitrite assay. Cell viability was evaluated using the 3-(4,5dimethylthiazol-2-yl)-2,5-diphenyltetrazolium bromide method (Mosmann 1983). Medium nitrite concentration was measured as an indicator of NO production using Griess reaction (Kim et al. 1995). The NO-suppressing effect of herbal tea extracts was expressed as the IC50 which denotes the concentration of herbal tea extracts causing $50 \%$ inhibition of NO production by LPS-activated RAW 264.7 cells.

\section{Statistical analysis}

All experiments were designed to include three replicates. Least Significant Difference was used to determine the differences among the 50 tomato accessions using IBM SPSS Statistics ver. 20 (IBM Co., Armonk, NY, USA). Clustering analysis and correlation analysis were also performed. Hierarchical clustering was performed using the $\mathrm{R}$ statistical software environment (http://www.r-project.org). Distances were calculated using complete linkage clustering and Pearson's correlation analysis. A $P<0.05$ was considered to be statistically significant.

\section{RESULTS}

\section{Flavonol and glycoalkaloid contents in the $\mathbf{5 0}$ tomato accessions}

The main descriptive statistics of five flavonols and two glycoalkaloids are summarized in Table 1. Quercetin content had the largest variance $(114.9 \%)$, with values ranging from 9.0 to $413.2 \mathrm{mg} / 100 \mathrm{~g}$. Quercetin was detected in 24 tomato accessions, with IT229711 showing the highest content $(429.7 \mathrm{mg} / 100 \mathrm{~g}$, Supplementary Table 1). Kaempferol was detected in all tomato accessions, with content values ranging from 3.2 to $81.2 \mathrm{mg} / 100 \mathrm{~g}$. IT236523 showed the highest kaempferol content (81.2 $\mathrm{mg} / 100 \mathrm{~g}$ ) while IT201650 had the lowest kaempferol content $(3.2 \mathrm{mg} / 100 \mathrm{~g})$. Myricetin had the smallest variance $(27.7 \%)$ among five flavonols whose content values ranging from 1.3 to $4.8 \mathrm{mg} / 100 \mathrm{~g}$. Of the 50 tomato 
accessions, myricetin were detected in all accessions except two (IT265355 and IT265357). Naringenin had the highest level among five flavonols in tomato leaves, although it was detected in 15 tomato accessions. Isorhamnetin was only detected in seven accessions. Its content ranged from 1.0 to $10.3 \mathrm{mg} / 100 \mathrm{~g}$.

Tomatine and tomatidine were detected in all tomato leaves. Their levels ranged from 209.4 to $925.6 \mathrm{mg} / 100 \mathrm{~g}$ and 25.0 to $110.4 \mathrm{mg} / 100 \mathrm{~g}$, respectively. Among the 50 tomato accessions, IT207224 had the highest tomatine content $(925.6 \mathrm{mg} / 100 \mathrm{~g})$. A total of 13 tomato accessions had high tomatidine contents. They did not show significant $(P>0.05)$ difference.

Table 1. Descriptive statistics of five flavonols, two glycoalkaloids, and four antioxidant activities in leaf extracts of 50 tomato accessions.

\begin{tabular}{clrrrrrrrr}
\hline \hline Group & \multicolumn{1}{c}{ Variable } & No. acc. & Minimum & Maximum & Average & \multicolumn{1}{c}{ SD } & CV (\%) & Skewness & Kurtosis \\
\hline Flavonol & Myricetin & 48 & 1.3 & 4.8 & 2.9 & 0.8 & 27.6 & -0.2 & -0.3 \\
$\left(\mathrm{mg} \mathrm{g}^{-1}\right)$ & Quercetin & 24 & 9.0 & 413.2 & 119.9 & 137.7 & 114.8 & 1.2 & -0.1 \\
& Naringenin & 15 & 23.2 & $1,306.4$ & 429.7 & 410.3 & 95.5 & 0.9 & -0.5 \\
& Kaempferol & 50 & 3.2 & 81.2 & 15.7 & 11.8 & 75.2 & 3.9 & 19.9 \\
& Isorhamnetin & 7 & 1.0 & 10.3 & 6.7 & 2.9 & 43.3 & -1.4 & 3.4 \\
Glycoalkaloid & Tomatine & 50 & 209.4 & 925.6 & 483.1 & 164.8 & 34.1 & 0.6 & 0.1 \\
$\left(\mathrm{mg} \mathrm{g}^{-1}\right)$ & Tomatidine & 50 & 25.0 & 110.4 & 61.3 & 20.3 & 33.1 & 0.7 & 0.1 \\
Antioxidant & DPPH (\%) & 50 & 10.3 & 39.5 & 22.7 & 6.5 & 28.6 & 0.8 & 0.4 \\
activity & ABTS (\%) & 50 & 21.3 & 59.7 & 40.9 & 8.0 & 19.6 & 0.0 & 0.0 \\
& TPC (mg GAE g & \\
& NO $\left(\mathrm{IC}^{50}\right)$ & 50 & 16.8 & 59.9 & 30.7 & 7.9 & 25.9 & 1.4 & 2.9 \\
& 50 & 24.8 & 71.5 & 36.9 & 7.2 & 19.5 & 0.3 & 1.1 \\
\hline
\end{tabular}

${ }^{2)} \mathrm{SD}$ : standard deviation, CV: coefficient of variation, DPPH: 2,2-diphenyl-1-picryl hydrazyl, ABTS: 2,2'-azino-bis (3-ethylbenzothiazoline-6-sulphonic acid), TPC: total polyphenol content, GAE: gallic acid equivalents, NO: nitric oxide.

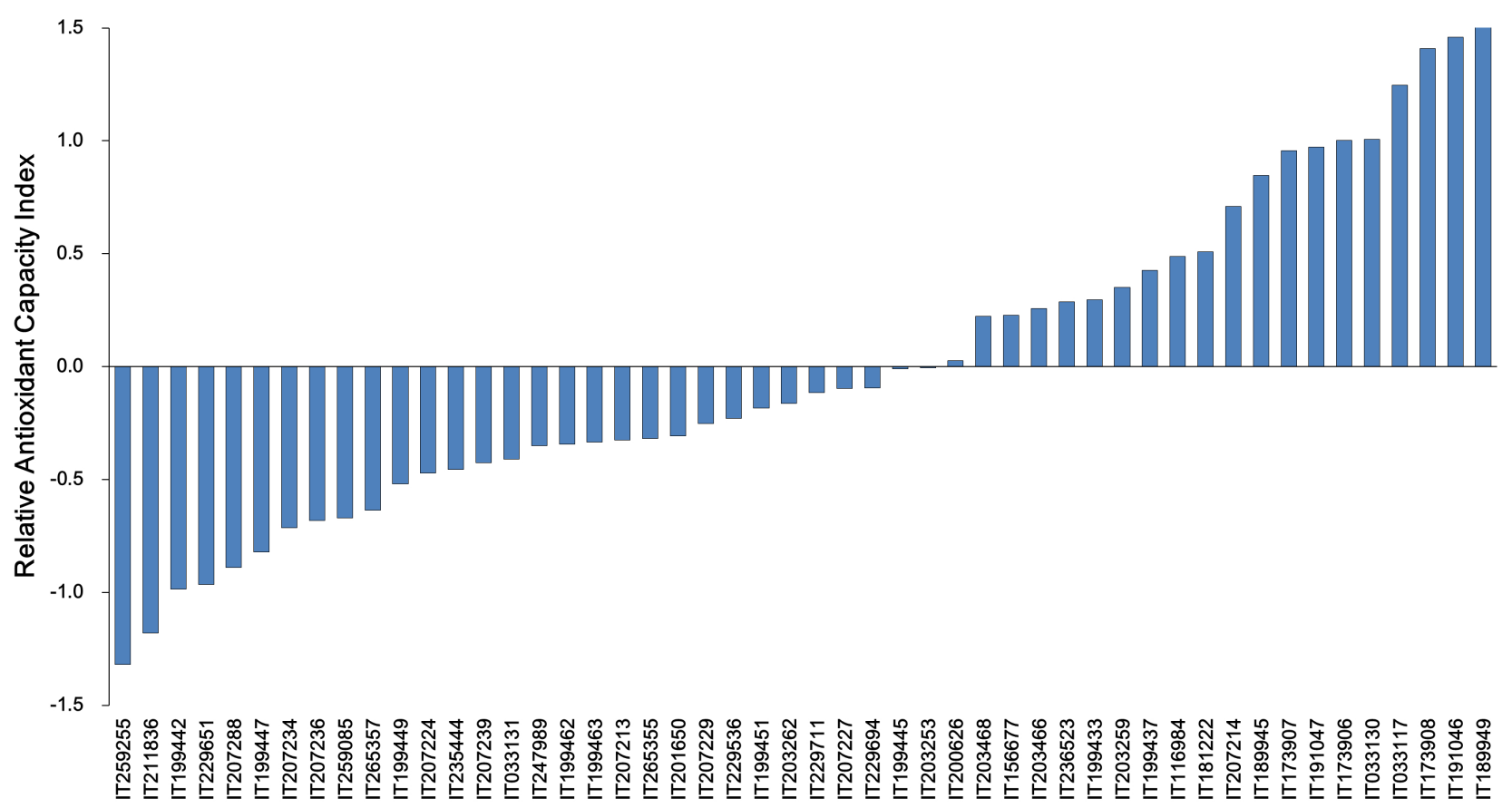

Fig. 1. Relative antioxidant capacity index of leaf extracts of 50 tomato accessions. 


\section{Antioxidant activities of 50 tomato accessions}

In antioxidant activities, $\mathrm{NO}$ had the smallest variance (19.5\%), with values ranging from 24.8 to $71.5 \mu \mathrm{l}$ (IC50). DPPH and ABTS values ranged from 10.3 to 39.5 and $21.3 \%$ to $59.7 \%$, respectively. Among the 50 tomato accessions, IT 191046 had the highest level of DPPH, while IT033117 and IT189949 had the highest level of ABTS. TPC ranged from 16.8 to 59.9 (mg GAE/100 g), with IT207214 having the highest level $(59.9 \pm 0.0 \mathrm{mg}$ GAE/100 g). To compare data obtained by different chemical methods used to evaluate antioxidant activities, relative antioxidant capacity index (RACI) was calculated (Fig. 1). Results of NO expressed as IC50 were converted using 1/IC50 before RACI calculation. Our results revealed that IT189949 had the highest RACI (1.58), followed by IT191046 (1.46). Positive values of RACI were obtained for 21 accessions. The tomato accession that showed the lowest RACI was IT259255 (-1.32).

\section{Principal component analysis analysis}

Results of principal component analysis (PCA) analysis are summarized in Table 2. The first four main principal components (PCs) were extracted from complicated components. Total cumulative variance of these four factors amounted to be $74.3 \%$. These components had Eigen values $>1$. The PCA grouped these tomato leaves into four main components, with PC1, PC2, PC3, and PC4 accounting for about $32.1 \%, 21.7 \%, 11.2 \%$, and $9.3 \%$ of the variation, respectively (Table 2). The first PC was related to flavonols. It had contributing traits such as quercetin, naringenin, and isorhamnetin content. The second PC was related to antioxidant activity. It had contributing traits such as DPPH and ABTS. The third PC was related to tomatine and TPCs. The fourth PC was related to kaempferol and tomatine contents. The distribution of tomato accessions in PCA analysis is shown in Fig. 2. After placing an ellipse around the data representing 95\% confidence interval using Hotelling's T2 statistic, all tomato accessions were observed except four accessions (IT229711, IT235444, IT265355, and IT265357). The four tomato accessions showed higher flavonol contents than other accessions.

\section{Correlation among the parameters of 50 tomato accessions}

The correlations among five flavonols, two glycoalkaloids, and four antioxidant activities are summarized in Table 3.

Table 2. Principal component analysis of five flavonols, two glycoalkaloids, and four antioxidant activities explained by the first four main components.

\begin{tabular}{lcccc}
\hline \hline Principal component & 1 & 2 & 3 & 4 \\
\hline Eigen value & 3.53 & 2.38 & 1.23 & 1.03 \\
\% of variance & 32.1 & 21.7 & 11.2 & 9.3 \\
Cumulative \% & 32.1 & 53.7 & 64.9 & \\
Component matrix & & & -0.071 & 0.081 \\
$\quad$ Myricetin & -0.298 & 0.333 & 0.020 & -0.132 \\
Quercetin & 0.484 & 0.157 & 0.074 & -0.132 \\
Naringenin & 0.475 & 0.204 & 0.156 & 0.592 \\
Kaempferol & 0.194 & 0.322 & 0.109 & 0.131 \\
Isorhamnetin & 0.441 & 0.272 & 0.424 & 0.575 \\
Tomatine & -0.202 & -0.088 & -0.264 & 0.284 \\
Tomatidine & -0.017 & -0.328 & -0.357 & 0.014 \\
DPPH & -0.218 & 0.420 & -0.298 & 0.132 \\
ABTS & -0.172 & 0.494 & 0.643 & -0.177 \\
TPC & -0.193 & 0.142 & 0.272 & -0.363 \\
NO & -0.251 & 0.298 & & \\
\hline
\end{tabular}

${ }^{2)}$ DPPH: 2,2-diphenyl-1-picryl hydrazyl, ABTS: 2,2'-azino-bis(3-ethylbenzothiazoline-6-sulphonic acid), TPC: total polyphenol content, NO: nitric oxide. 


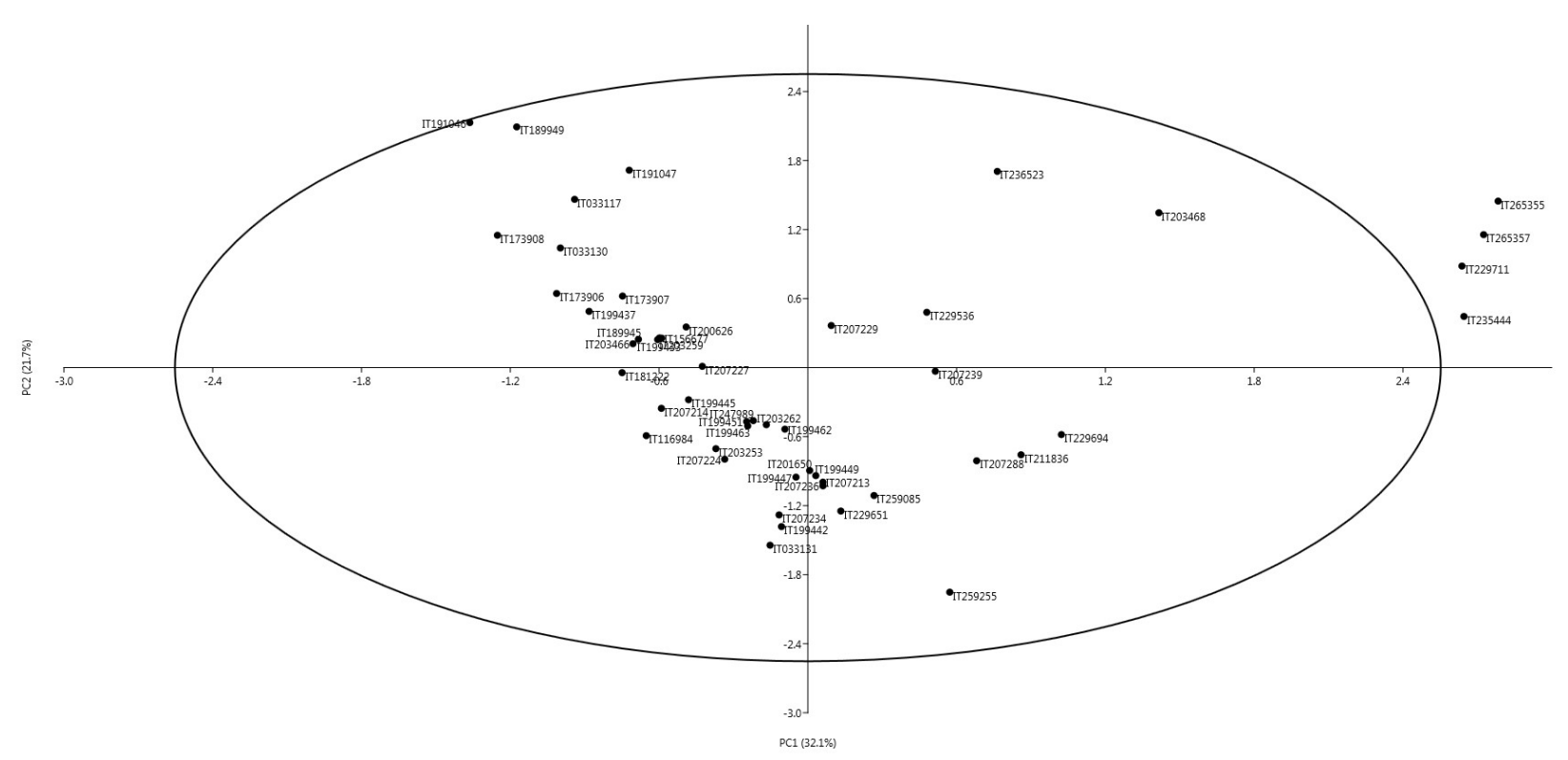

Fig. 2. Two-dimensional scatter diagram of principal component analysis (PCA) for leaf extracts of the 50 tomato accessions based on five flavonols, two glycoalkaloids, and four antioxidant activities.

Table 3. Correlation coefficients between traits in leaf extracts of the 50 tomato accessions.

\begin{tabular}{|c|c|c|c|c|c|c|c|c|c|c|c|}
\hline & Myricetin & Quercetin & Naringenin & Kaempferol & isorhamnetin & Tomatine & Tomatidine & DPPH & ABTS & TPC & $\mathrm{NO}$ \\
\hline Quercetin & $-0.646^{* *}$ & & & & & & & & & & \\
\hline Naringenin & -0.548 & $0.895^{* *}$ & & & & & & & & & \\
\hline Kaempferol & 0.079 & 0.099 & 0.416 & & & & & & & & \\
\hline isorhamnetin & -0.518 & 0.725 & $0.975^{* *}$ & 0.128 & & & & & & & \\
\hline Tomatine & 0.100 & $-0.469^{*}$ & -0.160 & 0.012 & -0.490 & & & & & & \\
\hline Tomatidine & -0.244 & 0.079 & 0.078 & -0.181 & -0.145 & 0.075 & & & & & \\
\hline $\mathrm{DPPH}^{\mathrm{z}}$ & $0.393^{* *}$ & -0.156 & -0.050 & 0.104 & 0.073 & -0.060 & -0.131 & & & & \\
\hline ABTS & $0.528 * *$ & -0.027 & 0.257 & 0.182 & $0.775^{*}$ & 0.012 & -0.179 & $0.702 * *$ & & & \\
\hline ТPC & 0.181 & -0.182 & -0.170 & 0.039 & -0.194 & 0.189 & -0.163 & 0.089 & 0.072 & & \\
\hline NO & $0.375^{* *}$ & -0.195 & 0.033 & -0.129 & 0.107 & 0.136 & -0.173 & $0.377^{* *}$ & $0.349^{*}$ & $0.430 * *$ & \\
\hline RACI & $0.522 * *$ & -0.178 & 0.042 & 0.074 & 0.384 & 0.095 & -0.233 & $0.765^{* *}$ & $0.749 * *$ & $0.560 * *$ & 0.760 ** \\
\hline
\end{tabular}

*** Significant at $P<0.05$ and $P<0.01$, respectively.

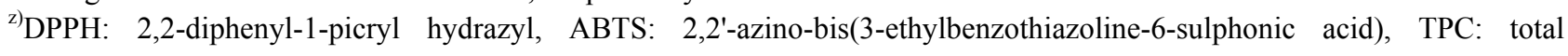
polyphenol content, NO: nitric oxide.

Kaempferol did not show any correlation with the 12 parameters. Naringenin showed positive correlations with quercetin $(\mathrm{r}=0.859, P<0.01)$ and isorhamnetin $(\mathrm{r}=0.975$, $P<0.01)$. Quercetin had negative correlations with myuricetin $(\mathrm{r}=-0.646, P<0.01)$ and tomatine $(\mathrm{r}=-0.469$, $P<0.05)$. Among the 12 characters, myricetin showed positive correlations with the following three antioxidant activities: DPPH ( $\mathrm{r}=0.393, P<0.01)$, NO ( $\mathrm{r}=0.375$, $P<0.01)$, and RACI $(\mathrm{r}=0.522, P<0.01)$. ABTS had positive correlation with isorhamnetin $(\mathrm{r}=0.775, P<0.05)$.

\section{Clustering analysis of 50 tomato accessions based on flavonols and glycoalkaloids contents}

All tomato accessions were clustered into four groups based on five flavonols and two glycoalkaloids except IT236523 (Fig. 3, Table 4). IT236523 showed the highest kamepferol content $(81.2 \pm 1.3 \mathrm{mg} / 100 \mathrm{~g})$. Group I consisted of five accessions with the highest quercetin 

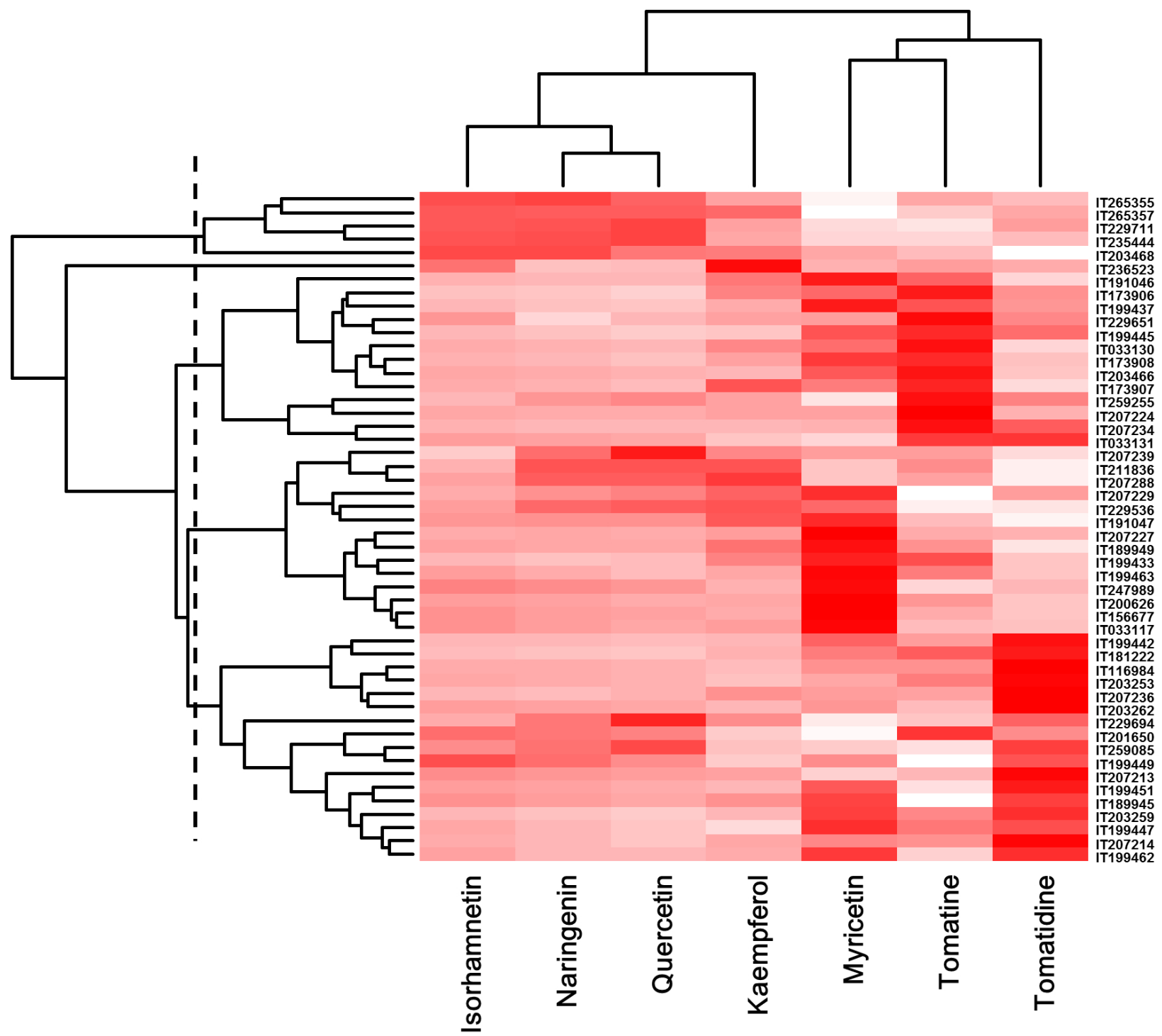

Fig. 3. Hierarchical clustering analysis of five flavonols and two glycoalkaloids in leaf extracts of 50 tomato accessions.

content $(342.2 \pm 90.8 \mathrm{mg} / 100 \mathrm{~g})$ and naringenin content $(960 \pm 203 \mathrm{mg} / 100 \mathrm{~g})$ but the lowest myricetin content $(1.89 \pm 0.90 \mathrm{mg} / 100 \mathrm{~g})$. Group II consisted of 13 accessions with the highest tomatine content $(702 \pm 102 \mathrm{mg} / 100 \mathrm{~g})$ without detectable naringenin. Group III consisted of 14 accessions with high myricetin content $(3.37 \pm 0.64 \mathrm{mg} / 100$ g). Group IV consisted of 17 accessions with the highest tomatidine content $(79.3 \pm 19.4 \mathrm{mg} / 100 \mathrm{~g})$. Among the five flavonols, only isorhamnetin was detected in Group I. The four groups did not show significant difference in antioxidant activities.

\section{DISCUSSION}

Information concerning phenolic substances found in plant byproducts is limited, especially the constituents of plant fractions. Most studies have evaluated phenolic constituents of fruit byproducts (Elbadrawy and Sello 2011; Taveira et al. 2012). Few studies have focused on whole tomato plant, although the properties of tomato fruits have been extensively studied (Silva-Beltrán et al. 2015). A recent investigation has revealed that tomato plant leaves have several active metabolites, including phenolic compounds and steroidic alkaloids (Taveira et al. 2012). 


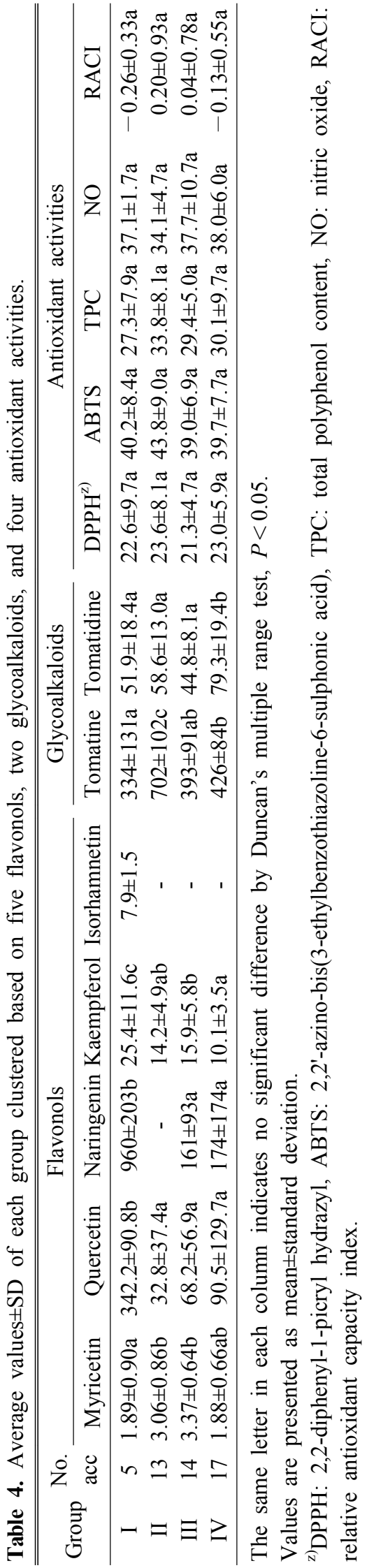

Sánchez-Rodríguez et al. (2012) have reported that quercetin and kaempferol are major components in tomato leaves. In this study, we investigated five flavonols and two glycoalkaloids in 50 tomato leaves. We confirmed that these tomato leaves didn't containe only quercetin and kaempferol, but also abundant naringenin and tomatine (Table 1).

In this study, flavonols contents of 50 tomato accessions were evaluated (Supplementary Table 1). Among the 50 tomato accessions, IT229711, IT265355, and IT236523 showed the highest contents of quercetin, naringenin, and kaempferol, respectively. Flavonoids, in particular those belonging to the class of flavonols (such as kaempferol and quercetin), are potentially health-protecting components in human diet due to their high antioxidant capacity and their ability of inducing human protective enzyme systems (Dugas et al. 2000; Duthie and Crozier 2000; Ng et al. 2000; Shih et al. 2000). These findings suggest that flavonoids might offer protection against major diseases such as coronary heart diseases and cancer (Hertog and Hollman 1996; Steinmetz and Potter 1996; Trevisanato and Kim 2000). In addition, several epidemiological studies have suggested a direct relationship between cardioprotection and consumption of flavonols from dietary sources (Hertog et al. 1993; Keli et al. 1996). Our results showed the possibility of using tomato leaves as new sources of antioxidant materials.

Tomato leaves contain glycoalkaloids similar to solanine. Toxic glycoalkaloids are not usually detectable in the fruit (Friedman and Levin 1995). Tomatidine, the basic aglycone of glycoalkaloids ( $\alpha$-tomatine and dehydrotomatine) in the tomato plant, can aid the defense of tomato plant against bacteria, fungi, viruses, and insects (Barceloux 2009). Friedman et al. (2000) have reported that tomatine has a strong affinity to cholesterol in vitro. They suggested that the low oral toxicity of tomatine might be due to its ability of forming an insoluble complex with cholesterol in vivo which can then be eliminated through feces. Kozukue et al. (2004) have suggested that biosynthesis/degradation of dehydrotomatine and $\alpha$-tomatine may be under distinct genetic control in the leaves of tomato plants. In this study, the contents of tomatine and tomatidine in the 50 tomato accessions were measured (Table 1). Tomatine and toma- 
tidine contents ranged from 209.4 to $925.6 \mathrm{mg} / 100 \mathrm{~g}$ and 25.0 to $110.4 \mathrm{mg} / 100 \mathrm{~g}$, respectively. Various contents of glycoalkaloids in these 50 tomato accessions might have been caused by various genetic background.

In this study, the antioxidant capacities of 50 tomato leaves were measured using four evaluation methods (DPPH, ABTS, TPC, and NO). Many evaluation methods for antioxidant capacity have been developed. Their merits and disadvantages have been fully discussed in several reviews (Halliwell et al. 1995; Frankel and Meyer 2000; Prior et al. 2005; Roginsky and Lissi 2005; MacDonaldWicks et al. 2006). However, each method of measuring antioxidant capacity has its own limitations because multiple reaction mechanisms and different phase locations can affect the measurements of antioxidant capacity (Sun and Tanumihardjo 2007). Therefore, Sun and Tanumihardjo (2007) have proposed RACI. The key advantage of RACI is that it is a numerical scale that can integrate multiple chemical methods, thus allowing comparison of antioxidant capacity of a large number of samples. Our results showed that the 50 tomato leaves had different rankings in antioxidant capacity (Supplementary Table 1). To compare data obtained by different chemical methods used to evaluate antioxidant activity, we used RACI of the 50 tomato leaves (Fig. 1). It appeared that the results of RACI could be used to select tomato accessions with high antioxidant activity in leaves so that new breeding materials can be developed.

Our results revealed the presence of five flavonols and two glycoalkaloids in tomato leaves. In addition, antioxidant activities of tomato leaves were determined using four evaluation methods (DPPH, ABTS, TPC, and NO). In the agro-industry, various beneficial properties of plant byproducts have been documented (Silva-Beltrán et al. 2015). This study opens up new possibilities of developing tomato leaves that contain phytochemicals by selection or commercial breeding. This strategy could be used to improve other underutilized crops.

\section{ACKNOWLEDGEMENTS}

This research was supported by a Research Program
(Code no. PJ010153) of Agricultural Science and Technology Development funded by National Institute of Agricultural Science, Rural Development Administration, Republic of Korea.

\section{REFERENCES}

Ajila CM, Prasada Rao UJ. 2008. Protection against hydrogen peroxide induced oxidative damage in rat erythrocytes by Mangifera indica L. peel extract. Food Chem. Toxicol. 46: 303-309.

Barceloux DG. 2009. Potatoes, tomatoes, and solanine toxicity (Solanum tuberosum L., Solanum lycopersicum L.). Dis. Mon. 55: 391-402.

Buer CS, Imin N, Djordjevic MA. 2010. Flavonoids: new roles for old molecules. J. Integr. Plant Biol. 52: 98-111.

Dugas AJ Jr, Castañeda-Acosta J, Bonin GC, Price KL, Fischer NH, Winston GW. 2000. Evaluation of the total peroxyl radical-scavenging capacity of flavonoids: structure-activity relationships. J. Nat. Prod. 63: 327-331.

Duthie G, Crozier A. 2000. Plant-derived phenolic antioxidants. Curr. Opin. Lipidol. 11: 43-47.

Elbadrawy E, Sello A. 2011. Evaluation of nutritional value and antioxidant activity of tomato peel extracts. Arab J. Chem. doi:10.1016/j.arabjc.2011.11.011. [Epub ahead of print]

Ferreres F, Taveira M, Gil-Izquierdo A, Oliveira L, Teixeira T, Valentão P, et al. 2011. High-performance liquid chromatography-diode array detection-electrospray ionization multi-stage mass spectrometric screening of an insect/plant system: the case of Spodoptera littoralis/ Lycopersicon esculentum phenolics and alkaloids. Rapid Commun. Mass Spectrom. 25: 1972-1980.

Frankel EN, Meyer AS. 2000. The problems of using one-dimensional methods to evaluate multifunctional food and biological antioxidants. J. Sci. Food Agri. 80: 1925-1941.

Friedman M. 2002. Tomato glycoalkaloids: role in the plant and in the diet. J. Agric. Food Chem. 50: 5751-5780.

Friedman M. 2013. Anticarcinogenic, cardioprotective, and other health benefits of tomato compounds lycopene, $\alpha$-tomatine, and tomatidine in pure form and in fresh and processed tomatoes. J. Agric. Food Chem. 61: 9534-9550.

Friedman M, Fitch TE, Yokoyama WE. 2000. Lowering of 
plasma LDL cholesterol in hamsters by the tomato glycoalkaloid tomatine. Food Chem. Toxicol. 38: 549-553.

Friedman M, Levin CE. 1995. Alpha-tomatine content in Tomato and Tomato products determined by Hplc with pulsed amperometric detection. J. Agric. Food Chem. 43: 1507-1511.

Halliwell B, Murcia MA, Chirico S, Aruoma OI. 1995. Free radicals and antioxidants in food and in vivo: what they do and how they work. Crit. Rev. Food Sci. Nutr. 35: 7-20.

Herrmann K. 1976. Flavonols and flavones in food plants: a review. Int. J. Food Sci. Technol. 11: 433-448.

Hertog MG, Feskens EJ, Hollman PC, Katan MB, Kromhout D. 1993. Dietary antioxidant flavonoids and risk of coronary heart disease: the zutphen elderly study. Lancet 342: 1007-1011.

Hertog MG, Hollman PC. 1996. Potential health effects of the dietary flavonol quercetin. Eur. J. Clin. Nutr. 50: 63-71.

Hopia A, Heinonen M. 1999. Antioxidant activity of flavonol aglycones and their glycosides in methyl linoleate. J. Am. Oil Chem. Soc. 76: 139-144.

Keli SO, Hertog MG, Feskens EJ, Kromhout D. 1996. Dietary flavonoids, antioxidant vitamins, and incidence of stroke: the Zutphen study. Arch. Intern. Med. 156: 637-642.

Khalid A, Zaheer-ul-Haq, Ghayur MN, Feroz F, Atta-urRahman, Gilani AH, et al. 2004. Cholinesterase inhibitory and spasmolytic potential of steroidal alkaloids. J. Steroid Biochem. Mol. Biol. 92: 477-484.

Kim H, Lee HS, Chang KT, Ko TH, Baek KJ, Kwon NS. 1995. Chloromethyl ketones block induction of nitric oxide synthase in murine macrophages by preventing activation of nuclear factor-kappa B. J. Immunol. 154: 4741-4748.

Kozukue N, Han JS, Lee KR, Friedman M. 2004. Dehydrotomatine and alpha-tomatine content in tomato fruits and vegetative plant tissues. J. Agric. Food Chem. 52: 2079-2083.

Lee DJ, Lee JY. 2004. Antioxidant activity by DPPH assay. Korean J. Crop Sci. 49: 187-194.

MacDonald-Wicks LK, Wood LG, Garg ML. 2006. Methodology for the determination of biological antioxidant capacity in vitro: a review. J. Sci. Food Agri. 86: 2046-2056.

Milner SE, Brunton NP, Jones PW, O'Brien NM, Collins SG, Maguire AR. 2011. Bioactivities of glycoalkaloids and their aglycones from Solanum species. J. Agric. Food Chem. 59: 3454-3484.

Mosmann T. 1983. Rapid colorimetric assay for cellular growth and survival: application to proliferation and cytotoxicity assays. J. Immunol. Methods 65: 55-63.

Mossi AJ, Cansian RL, Carvalho AZ, Dariva C, Oliveira JV, Mazutti M, et al. 2004. Extraction and characterization of volatile compounds in Maytenus ilicifolia, using highpressure CO2. Fitoterapia 75: 168-178.

$\mathrm{Ng}$ TB, Liu F, Wang ZT. 2000. Antioxidative activity of natural products from plants. Life Sci. 66: 709-723.

Nordberg J, Arnér ES. 2001. Reactive oxygen species, antioxidants, and the mammalian thioredoxin system. Free Radic. Biol. Med. 31: 1287-1312.

Prior RL, Wu X, Schaich K. 2005. Standardized methods for the determination of antioxidant capacity and phenolics in foods and dietary supplements. J. Agric. Food Chem. 53: 4290-4302.

Re R, Pellegrini N, Proteggente A, Pannala A, Yang M, Rice-Evans C. 1999. Antioxidant activity applying an improved ABTS radical cation decolorization assay. Free Radic. Biol. Med. 26: 1231-1237.

Roginsky V, Lissi EA. 2005. Review of methods to determine chain-breaking antioxidant activity in food. Food Chem. 92: $235-254$.

Sánchez-Rodríguez E, Ruiz JM, Ferreres F, Moreno DA. 2012. Phenolic profiles of cherry tomatoes as influenced by hydric stress and rootstock technique. Food Chem. 134: 775-782.

Shih H, Pickwell GV, Quattrochi LC. 2000. Differential effects of flavonoid compounds on tumor promoterinduced activation of the human CYP1A2 enhancer. Arch. Biochem. Biophys. 373: 287-294.

Silva-Beltrán NP, Ruiz-Cruz S, Chaidez C, Ornelas-Paz Jde J, López-Mata MA, Márquez-Ríos E, et al. 2015. Chemical constitution and effect of extracts of tomato plants byproducts on the enteric viral surrogates. Int. J. Environ. Health Res. 25: 299-311.

Singh M, Kaur M, Kukreja H, Chugh R, Silakari O, Singh D. 2013. Acetylcholinesterase inhibitors as Alzheimer therapy: from nerve toxins to neuroprotection. Eur. J. Med. Chem. 70: 165-188.

Slimestad R, Verheul M. 2009. Review of flavonoids and other phenolics from fruits of different tomato (Lycopersicon esculentum Mill.) cultivars. J. Sci. Food 
Agri. 89: 1255-1270.

Steinmetz KA, Potter JD. 1996. Vegetables, fruit, and cancer prevention: a review. J. Am. Diet. Assoc. 96: 1027-1039.

Sun T, Tanumihardjo SA. 2007. An integrated approach to evaluate food antioxidant capacity. J. Food Sci. 72: R159-R165.

Taveira M, Ferreres F, Gil-Izquierdo A, Oliveira L, Valentão P, Andrade PB. 2012. Fast determination of bioactive compounds from Lycopersicon esculentum Mill. leaves. Food Chem. 135: 748-755.

Taveira M, Sousa C, Valentão P, Ferreres F, Teixeira JP, Andrade PB. 2014. Neuroprotective effect of steroidal alkaloids on glutamate-induced toxicity by preserving mitochondrial membrane potential and reducing oxidative stress. J. Steroid Biochem. Mol. Biol. 140: 106-115.

Trevisanato SI, Kim YI. 2000. Tea and health. Nutr. Rev. 58: $1-10$.

Tsai PJ, Tsai TH, Yu CH, Ho SC. 2007. Comparison of NO-scavenging and NO-suppressing activities of different herbal teas with those of green tea. Food Chem. 103: 181-187.

Waterhouse AL. 2001. Determination of total phenolics, p. I1.1.1-I1.1.8. In: R.E. Wrolstad (ed.). Current protocols in food analytical chemistry. John Wiley \& Sons, Inc., New York, NY.

Willcox JK, Ash SL, Catignani GL. 2004. Antioxidants and prevention of chronic disease. Crit. Rev. Food Sci. Nutr. 44: 275-295. 